\title{
A negrura em representações visuais no jornal Folha De S.Paulo e suas implicações para a identidade cultural do negro no Brasil ${ }^{1}$
}

\section{The blackness in visual representations in the Folha De S.Paulo newspaper and its implications for the cultural identity of black in Brazil}

Maria Ogécia Drigo² e Graziella Andreia Malago³

1 Uma primeira versão deste artigo foi apresentada no VII Congresso Internacional de AE-IC, "Comunicação e Diversidade", realizado entre 7 e 10 de julho de 2020, na Faculdade de Filologia, Tradução e Comunicação da Universidade de Valencia, Espanha. em Ciências da Comunicação pela Escola de Comunicações e Artes da Universidade de São Paulo (ECA-USP) e docente do Programa de Pós-Graduação em Comunicação e Cultura da Universidade de Sorocaba (Uniso). E-mail: maria.drigo@prof.uniso.br.

3 Doutoranda do Programa de Pós-Graduação em Comunicação e Cultura da Uniso e docente na mesma instituição. E-mail: graziella.malago@prof.uniso.br. 


\section{Resumo}

Com o propósito de contribuir para a compreensão do processo de construção social da negrura, este artigo apresenta questões sobre a construção de identidade do Negro, conforme Mbembe e busca inventariar significados e valores relativos à negrura, postos em circulação pelas representações visuais do jornal Folha de S.Paulo. A amostra compõe-se de 215 representações visuais agrupadas em categorias e analisadas via estratégias da semiótica peirceana. Entre os resultados, enfatiza-se que a publicidade agrega significados à negrura, o que pode contribuir para que o processo de construção da identidade cultural do Negro vá além da estrutura de submissão vinculada à escravidão e à (re)atualização da tradição ou à experiência originária. Esta pesquisa é relevante para a comunicação, pois traz reflexões sobre práticas socioculturais vinculadas a produtos midiáticos e à negrura.

Palavras-chave

Negrura, negro, representação visual.

\section{Abstract}

To contribute to the understanding of the process of social construction of blackness, this article presents questions about the construction of the Black identity, according to Mbembe and to inventory meanings and values related to blackness, put into circulation by the visual representations of the newspaper Folha de S.Paulo. The sample consists of 215 visual representations grouped into categories and analyzed using strategies from the Peircean semiotics. Among the results, we emphasize that advertising adds meanings to blackness, which can contribute to making the process the cultural identity of the Black person go beyond the submission structure linked to slavery and the (re)updating of tradition, or the original experience. This study is relevant for communication, since it presents reflections on of social and cultural practices related to media products and blackness.

\section{Keywords}

Blackness, black, visual representation. 


\section{Introdução}

Este artigo apresenta resultados de pesquisas que têm como tema o processo de construção social da negrura enquanto qualidades da cor preta, cor esta que se atualiza nos produtos midiáticos, de modo geral, em arranjos com outras cores, formas e texturas na composição da linguagem visual, bem como as que incluem representações de pessoas negras na sua composição. Com o objetivo de contribuir para a compreensão do processo de construção social da negrura por meio de representações visuais - desenhos, pinturas, fotografias, reproduções de imagens televisivas e cinematográficas, da publicidade e outras modalidades - veiculadas no jornal Folha de S.Paulo, apresentamos aspectos vinculados ao Negro, conforme Mbembe, e explicitamos os significados relativos à negrura postos em circulação pelas representações visuais que constam no jornal mencionado e no período especificado. O jornal foi selecionado por ser um dos de maior circulação no país.

A análise das representações visuais vale-se de estratégias elaboradas por Santaella (2018) a partir de conceitos da gramática especulativa, um dos ramos da semiótica ou lógica de Charles Sanders Peirce. A ciência dos signos proposta pelo lógico - como ele se autodenominava -, abarca todas as linguagens e parte do princípio de que nosso conhecimento se dá via signos, ou seja, de que o signo faz a mediação entre os fenômenos e a realidade. A análise semiótica requer do analista três tipos de capacidade: a de contemplar, que implica abrir as janelas do espírito e ver o que está diante dos olhos; a de distinguir, discriminar resolutamente diferenças nessas observações; e, por fim, a capacidade de generalizar as observações em classes ou categorias abrangentes. Assim, as interpretações - ou os possíveis interpretantes dessas representações visuais - contribuem para induzir possíveis mudanças de crenças, de ações e de sentimentos, no caso do artigo, envolvendo a negrura. Feitas as considerações iniciais, passamos a apresentar conceitos que sustentam os três tipos de olhar mencionados, que são necessários para a elaboração de uma análise semiótica, na perspectiva peirceana. 


\section{Sobre os signos e seus efeitos}

Charles Sanders Peirce (1839-1914), que se denominou lógico, fundou o pragmaticismo e a ciência geral dos signos - semiótica ou lógica -, que nos fornece definições e classificações de signos, dos quais emergem estratégias de análise de linguagens. Para Santaella (2011, p. 11-12), as linguagens envolvem uma "gama incrivelmente intrincada de formas sociais de comunicação e de significação que inclui a linguagem verbal articulada - a palavra escrita ou falada -, mas absorve também a linguagem dos surdos-mudos, o sistema codificado da moda, da culinária e tantos outros".

O signo representa o objeto e gera interpretantes. Ele constitui uma relação triádica com o objeto e o interpretante, fazendo a mediação entre o objeto e o interpretante. O interpretante, ou efeito, é um novo signo - para o mesmo objeto -, que gera outro interpretante. Tal processo, ou ação do signo - semiose -, é infinito. Extensivamente, entre nós e a realidade há uma camada de signos, ou há uma diversidade de linguagens, o que não impede o acesso à realidade, uma vez que o interpretante mantém o vínculo com o objeto. Entre nós e a realidade há uma camada de significados da negrura, no caso, que circulam com palavras, com representações visuais, em produtos midiáticos, em geral, e em obras de arte.

Mas tanto a definição de signo como suas classificações envolvem um primeiro modo de aparecer das coisas, antes de se fazerem signos, dado pelas categorias fenomenológicas. São três as categorias: primeiridade, secundidade e terceiridade, que implicam as três capacidades requeridas ao analista - contemplar, observar e generalizar - já mencionadas. A primeiridade - a primeira categoria que traz em si a ideia de primeiro, de que não há outro. Trata-se do modo de aparecer das qualidades, quando não encarnadas. A negrura, enquanto qualidades em potencial da cor preta - que independe de qualquer atualização, quando compõem uma representação visual, por exemplo - constitui uma experiência monádica, pois é indivisível, indescritível. A secundidade envolve dois, o outro. É uma relação binária caracterizada por um modo de aparecer objetal, que implica ação-reação, força bruta. 
Existe um mundo real, reativo, um mundo sensual, independente do pensamento e, no entanto, pensável, que se caracteriza pela secundidade. Esta é a categoria que a aspereza e o revirar da vida tornam mais familiarmente proeminente. É a arena da existência cotidiana. (SANTAELLA, 2011, p. 47)

A terceiridade é a categoria da mediação. Nela as leis, as normas, as regras são percebidas como operativas.

\footnotetext{
O azul, simples e positivo azul, é um primeiro. O céu, como lugar e tempo, aqui e agora, onde se encarna o azul, é um segundo. A síntese intelectual, elaboração cognitiva - o azul no céu, ou o azul do céu -, é um terceiro. (SANTAELLA, 2011, p. 51)
}

As categorias anunciadas possuem correlatos para os interpretantes. Assim são três tipos de interpretantes e um deles, por sua vez, também se subdivide. Conforme Drigo e Souza (2013, p. 24), o interpretante "é o produto da síntese intelectual e a ação do signo - semiose -, só se efetiva quando ele gera outro signo, ou seja, o interpretante não permanece como potencialidade, mas põe em ato o processo de significação do signo". O interpretante em potencial é o imediato e o interpretante final é aquele para o qual os dinâmicos tendem. Ele seria o interpretante ideal que só se alcança quando o objeto for retomado de modo suficiente, nas mais diversas semioses. Os interpretantes dinâmicos, os que se atualizam de fato, são classificados como: emocional, energético e lógico. "O primeiro efeito significativo de um signo é um sentimento produzido por ele" (PEIRCE, 1934, CP 5.475), que é o interpretante emocional. Ele pode "significar muito mais do que esse sentimento de reconhecimento; e, em alguns casos, é o único efeito significativo que o signo produz" (PEIRCE, 1934, CP 5.475). Mas, "se um signo produz qualquer efeito significativo adicional, ele o fará pela mediação do interpretante emocional, e esse efeito adicional sempre envolverá um esforço. Eu chamo de interpretante energético" (PEIRCE, 1934, CP 5.475). Peirce explica que tal esforço pode ser muscular, mas, de modo geral, é um esforço mental que não envolve significados de um conceito intelectual, pois ele é um ato. O interpretante lógico, sim, envolve conceitos intelectuais, que são de 
natureza geral. No entanto, o signo mental não pode ser o único interpretante lógico. Segundo Peirce, o único efeito mental - que não é um signo mental e isso é passível de prova:

É uma mudança de hábitos; significando, por mudança de hábito, uma modificação das tendências de uma pessoa em relação à ação, resultante de experiências anteriores ou de esforços anteriores de sua vontade ou atos, ou de um complexo de ambos os tipos de causa. (PEIRCE, 1934, CP 5. 476)

Cabe ao analista, portanto, identificar os aspectos qualitativos e os referenciais vinculados às leis e às normas que preponderam no signo, para assim elencar os possíveis interpretantes.

\section{Representações visuais da negrura e seus significados}

As representações visuais, um total de 215 , que constam no acervo online da Folha de S.Paulo, de $1^{\circ}$ a 31 de março de 2019, foram alocadas em categorias (Gráfico 1).

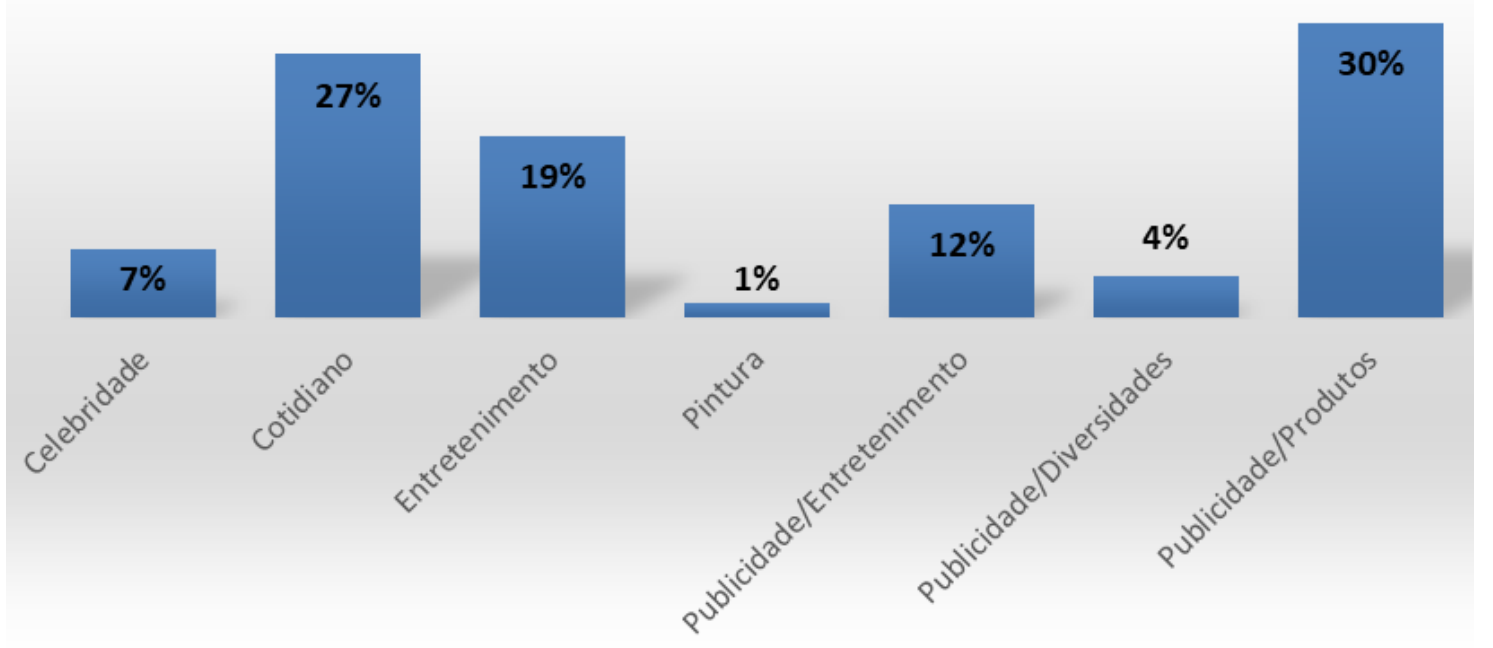


Gráfico 1: As representações visuais no jornal impresso Folha de S.Paulo, por modalidade, de $1^{\circ}$ a 31 de março de 2019

Fonte: Elaborado pelas autoras.

Podemos observar que $7 \%$ do total de representações visuais estão alocados na categoria celebridade; $27 \%$, na categoria cotidiano; $19 \%$, em entretenimento; $1 \%$ pertence à categoria pintura e, por fim, as representações de publicidade (99 representações visuais ou $46 \%$ do total) estão alocadas nas três últimas colunas no Gráfico 1, como publicidade/entretenimento, publicidade/diversidade e publicidade/produto ou marca. Selecionamos, para análise, uma representação visual para cada categoria, por sorteio. As figuras foram numeradas de 1 a 65, na categoria publicidade/produto, por exemplo, e um número foi sorteado.

Para a categoria celebridade foi sorteada a representação visual (Figura 1). Num primeiro momento, a representação visual incita um olhar observacional. Há uma cena composta com retratos de Barack e Michelle Obama, cada um deles ladeado pelo retratado e pelo pintor, flagrada em um evento na Galeria Nacional de Retratos, em Washington. A fotografia capta o momento em que uma pose do casal é registrada - via celular - por muitas pessoas e, possivelmente, por fotógrafos. A foto jornalística é um signo que apresenta o casal Obama e o retrato de Barack Obama e outro de Michele Obama, numa cerimônia na Galeria Nacional de Retratos. 


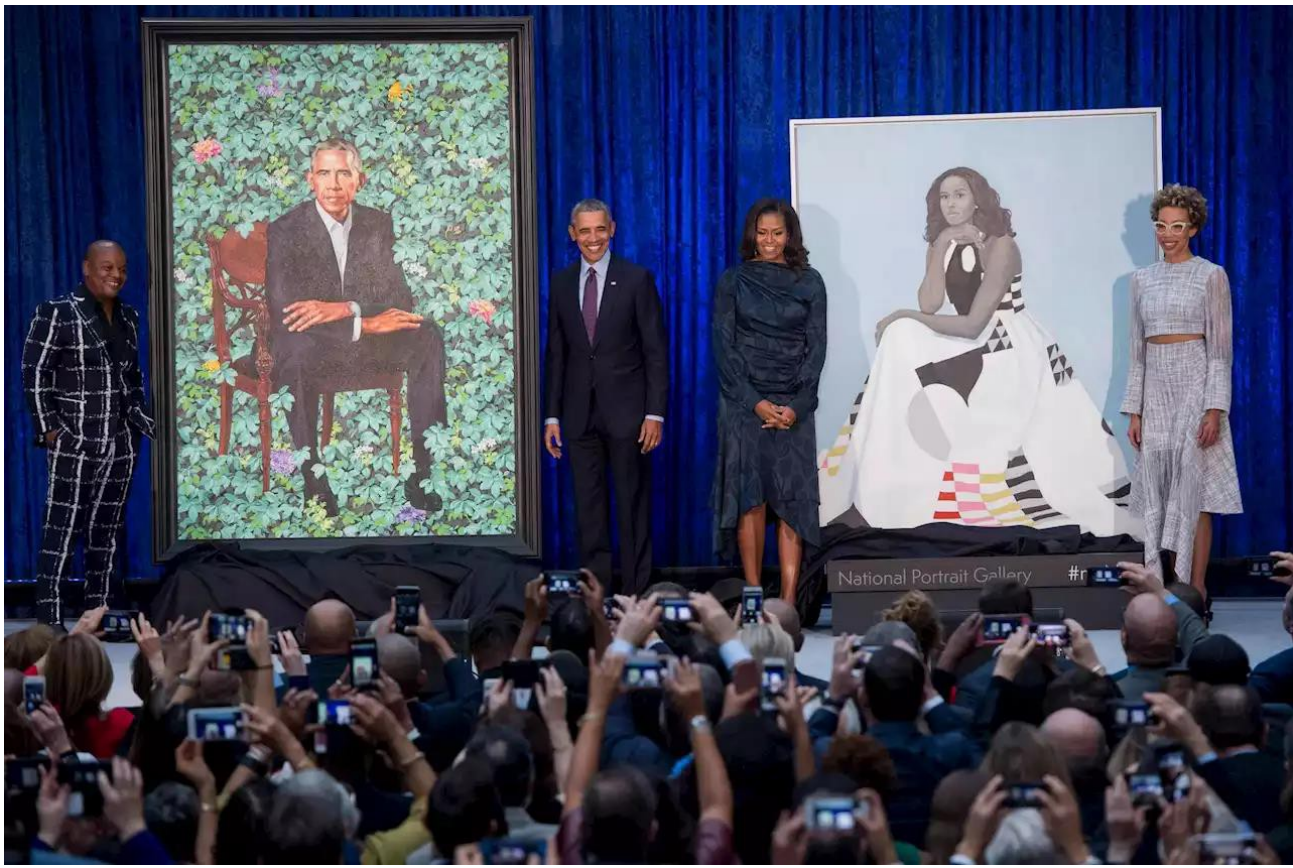

Figura 1: Retratos de Barack Obama e Michele Obama

Fonte: Folha de S.Paulo.

Há duas modalidades de objeto do signo, o imediato e o dinâmico, e o primeiro é o capturado pelo signo e adentra a semiose numa mente particular, enquanto o dinâmico envolve todo o contexto que poderá ainda ser contemplado em outras representações do mesmo objeto. O objeto dinâmico deste signo envolve os Obamas, não só como eles são retratados, mas como todas as informações relativas ao percurso do ex-presidente e da ex-primeira-dama dos Estados Unidos, bem como aspectos vinculados ao fato de ser ele o primeiro presidente negro do país e outras que também compõem a experiência colateral de possíveis intérpretes.

No que se refere ao fundamento, ou seja, em relação a algo que pode provocar modificações na mente de um intérprete (ou produz algum efeito no intérprete), ou se fazer signo, há três maneiras diferentes: pela qualidade, pela existência ou pelo caráter de lei. Quando um ou outro aspecto prevalece, então o signo, em relação ao seu fundamento, pode ser denominado qualissigno, sinsigno ou legissigno, respectivamente. O signo em relação ao seu objeto, ao objeto que sugere, apresenta ou representa, pode ser denominado ícone, 
índice ou símbolo, respectivamente. O ícone sugere o objeto por semelhança, o índice aponta para o objeto, apresenta o objeto ou parte dele, enquanto o símbolo representa o seu objeto, por meio de uma regra, convenção ou lei.

O objeto é apresentado na representação visual (Figura 1) e leva o intérprete a identificar imediatamente o casal Obama, pois a fotografia tem uma conexão real com o referente, ela testemunha ou registra um instante de um fato, logo pode prevalecer como índice. "Um índice envolve a existência de seu objeto" (PEIRCE, 1932, CP 2.315). Assim, a representação visual pode preponderar como sinsigno indicial, sendo sinsigno porque é um existente e indicial devido à conexão ao real. Os interpretantes que podem se atualizar, de modo preponderante, são os interpretantes dinâmicos energéticos, vinculados à constatação, à identificação dos elementos que compõem a representação visual. Vale destacar que, para um intérprete que não identifique o casal, o texto que compõe a notícia com a reprodução fotográfica contribui para a geração dos interpretantes mencionados.

Há elementos na representação visual que podem incitar a contemplação. O movimento capturado - braços erguidos e mãos sustentando celulares, prolongando o momento em que o casal Obama posa para fotos - remete o intérprete à euforia. O próprio retrato de Barack Obama, pelos aspectos qualitativos do plano de fundo verde - formado por folhas verdes - provoca sensação de leveza, pois a cadeira - um trono para o Negro, Barack Obama - parece flutuar. Michele Obama, por sua vez, é retratada com um vestido que pode levar o intérprete a associar a pintura a uma obra abstrata - poucas formas geométricas em meio à brancura - que se distancia de estereótipos de roupas dos africanos, com estampas coloridas - e, assim, amenizando o vínculo entre Negro e África. O vestido, que sobre o branco apresenta desenhos geométricos nas cores vermelha e preta, reforça a modernidade da cor preta, pois segundo Pastoureau (2011, p. 166), "após a Primeira Guerra Mundial, pintores, artistas gráficos, estilistas e costureiros restituem ao preto seus status de cor verdadeira, tornando-a um dos símbolos da modernidade". A representação visual, por uma fração mínima de instantes, por construir uma ambiência que mescla euforia, leveza e sofisticação, 
pode gerar interpretantes dinâmicos emocionais. Tais interpretantes podem contribuir ou até mesmo garantir a continuidade da semiose envolvendo o mesmo objeto. Outros interpretantes podem ser então gerados - os dinâmicos lógicos e entre eles há os que envolvem a questão do Negro.

A partir de Mbembe (2017), pode-se afirmar que a trajetória dos Obamas é muito significativa para o processo de construção da identidade cultural do Negro, pois reforça a fase em que o Negro afirma a sua identidade, no seu território, sem recorrer às marcas do passado ou dissociando-a da África. O Negro é apresentado, na representação visual, numa ambiência impregnada de leveza e requinte, o que pode contribuir para que outros aspectos do objeto dinâmico contexto do casal Obama - possam ser retomados em outras semioses alcançando interpretantes lógicos. Tais interpretantes podem propiciar a ressignificação de concepções e crenças dos intérpretes vinculadas ao Negro.

A outra representação visual que consta na mesma página do jornal (Figura 2) que registra um momento do desfile da Escola de Samba Estação Primeira de Mangueira, no carnaval, no Rio de Janeiro, em 2019 -, não consta da amostra, pois não apresenta a cor preta. No entanto, vale chamar a atenção para o fato de que o leitor - no caso - pode se envolver, ao percorrer a página com um olhar mais demorado ou ao realizar a leitura de outras notícias, na mesma página, que tratam da questão do Negro no Brasil. Neste desfile, a escola de samba - que foi a campeã recontou a história do Brasil por meio de heróis da resistência, negros e índios. 


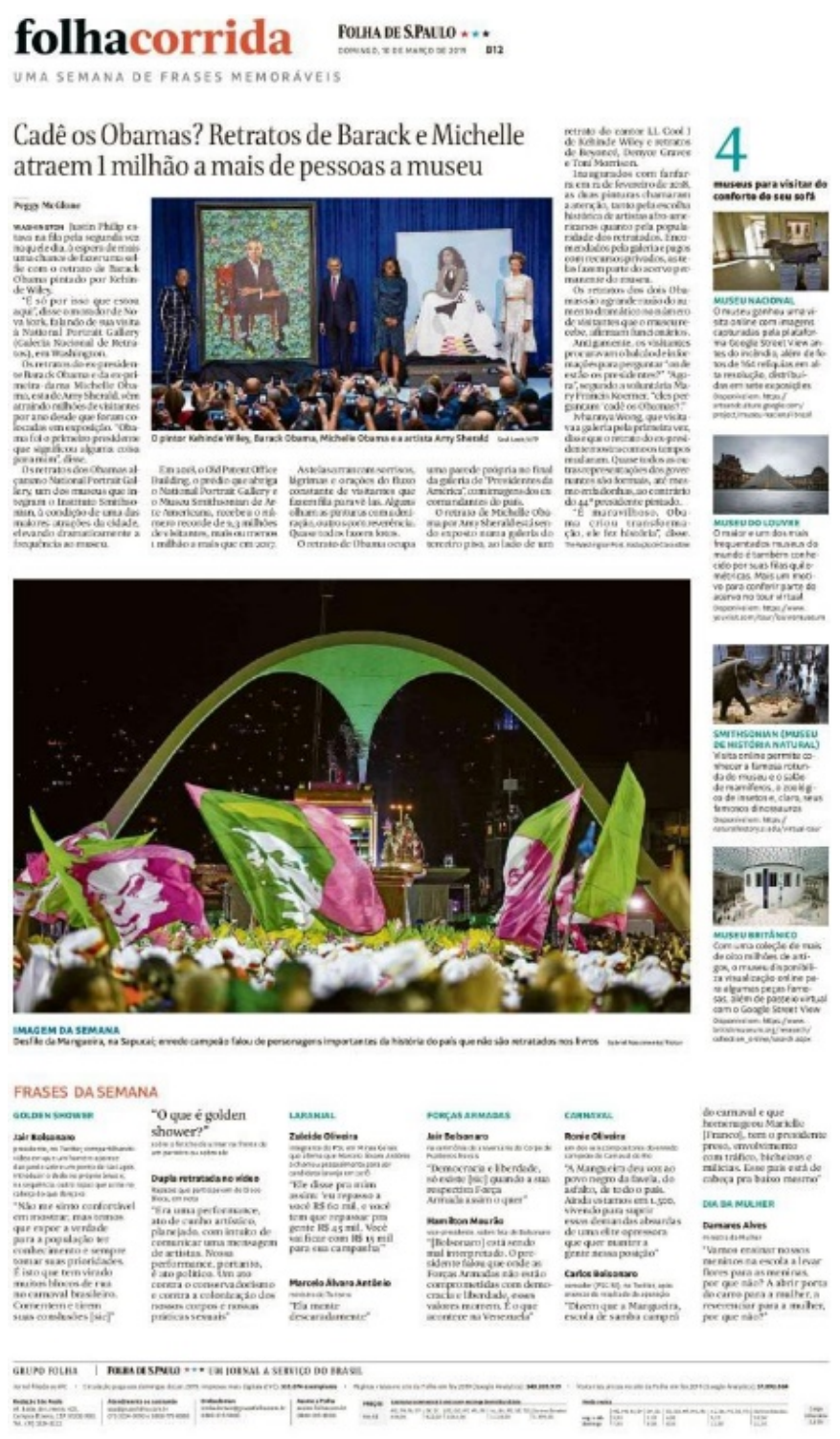

Figura 2: A notícia na página do jornal

Fonte: Folha de S.Paulo.

O processo de construção de identidade cultural do Negro abarca duas fases. A primeira busca respostas para a questão: quem é? Esta fase envolveu discursos e práticas, trabalho que "consistiu em inventar, contar, repetir e pôr em circulação fórmulas, textos, rituais com o objetivo de fazer acontecer o Negro enquanto sujeito de raça e exterioridade selvagem, passível a tal respeito, de desqualificação moral e de instrumentalização prática" (MBEMBE, 2017, p. 58). Com o tempo, a razão negra suscita outros questionamentos, colocados agora, como 
explica Mbembe (2017, p. 58-59), na primeira pessoa do singular: "quem sou eu?". A resposta a tal pergunta constitui uma declaração de identidade. Conforme ressalta Mbembe (2017, p. 59), nela "o Negro diz de si mesmo que é aquilo que não foi apreendido; aquele que não está onde se diz estar, e muito menos onde o procuramos, mas antes no lugar onde não é pensado". Nesse caso, o enredo da escola contribui para trazer à tona o encontro com duas fases da construção de identidade do Negro, pois ao mesmo tempo que reafirma as suas origens, atadas à África, ou à escravidão e suas consequências, coloca o Negro em um lugar onde não foi comumente pensado, como herói da resistência.

Ainda em relação ao racismo, pode-se observar - com as representações visuais selecionadas - que ele ganha proporções como as mencionadas por Mbembe (2017). Se historicamente a raça, nos regimes de segregação, instituía a lógica do recinto fechado, agora, na era da segurança, ela "é aquilo que permite identificar e definir que grupos de populações são, individualmente, portadores de traços diferenciais e mais ou menos aleatórios" (MBEMBE, 2017, p. 71). Trata-se de um racismo sem raça que se faz com a cultura e a religião tomando o lugar da biologia. Com ele, novas categorias racializadas permeiam o cotidiano. Sobre a lógica racista, Mbembe (2017, p. 72) adverte:

\footnotetext{
É falso pensar que a lógica racista é apenas um sintoma da depredação de classe ou que a luta de classes seja a última palavra da "questão social". É verdade que raça e racismo estão ligados a antagonismos assentes na estrutura econômica das sociedades. Mas não é certo que a transformação desta estrutura conduza inevitavelmente ao desaparecimento do racismo. Em grande parte da história moderna, raça e classe foram-se originando mutuamente. (MBEMBE, 2017, p. 72)
}

E ainda, no mundo moderno, tal lógica passa a ser transversal à estrutura social e econômica e está sempre em metamorfose. Indícios de tal transformação podem ser vistos na representação visual (Figura 3), que compõe notícia sobre as dificuldades enfrentadas pelos venezuelanos acolhidos no Brasil. Trata-se de uma representação visual alocada na categoria cotidiano, que foi também sorteada entre as que compõe a categoria. 


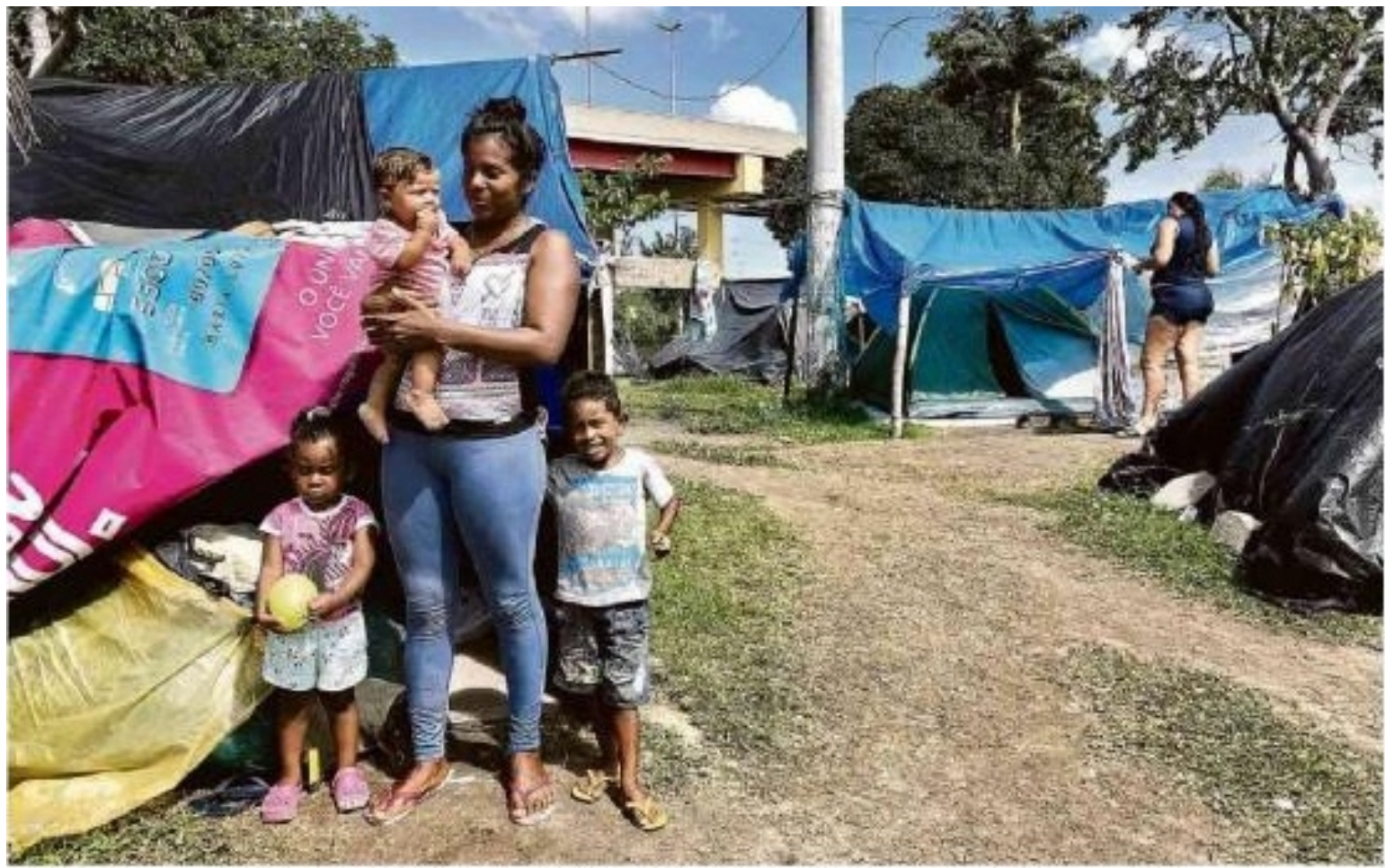

Figura 3: A cor preta enquanto indício de precariedade, isolamento, abandono Fonte: Folha de S.Paulo.

A representação visual, como a anterior, prevalece como um sinsigno a reprodução da fotografia indicial dicente, pois registra um momento, segundo Maisonave (2019), da situação que envolvia inúmeros imigrantes venezuelanos em um acampamento próximo à rodoviária de Manaus, capital do Amazonas, estado que faz fronteira com a Venezuela. Mas, para além do olhar observacional, que pode gerar interpretantes reativos para tal signo, há a possibilidade de se fazer conjeturas com o jogo de cores presente na representação visual. Dando corpo à precariedade, à degradação, há um jogo de cores - cor-de-rosa, amarelo, azul e preta - atualizados na cobertura das barracas, cujo efeito parece sucumbir diante da improvisação, da precariedade das moradias - cobertas com pláticos e sustentadas com paus e pedras. A cor preta atualizada em plástico - nessa ambiência - passa a ser traduzida também por precariedade, degradação, ou seja, ela toma o lugar dessas ideias, 
contribuindo para gerar outros interpretantes em que tais aspectos e a cor preta caminham juntos.

Em representações do cotidiano, a cor preta, atada aos negros - na categoria entretenimento - ganha significados em situações de euforia (Figura 4). A fotografia registra um momento de euforia de integrantes da escola de Samba Estação Primeira de Mangueira. O gesto - braços erguidos e mãos fechadas - pode ser visto como um resistência e solidariedade.

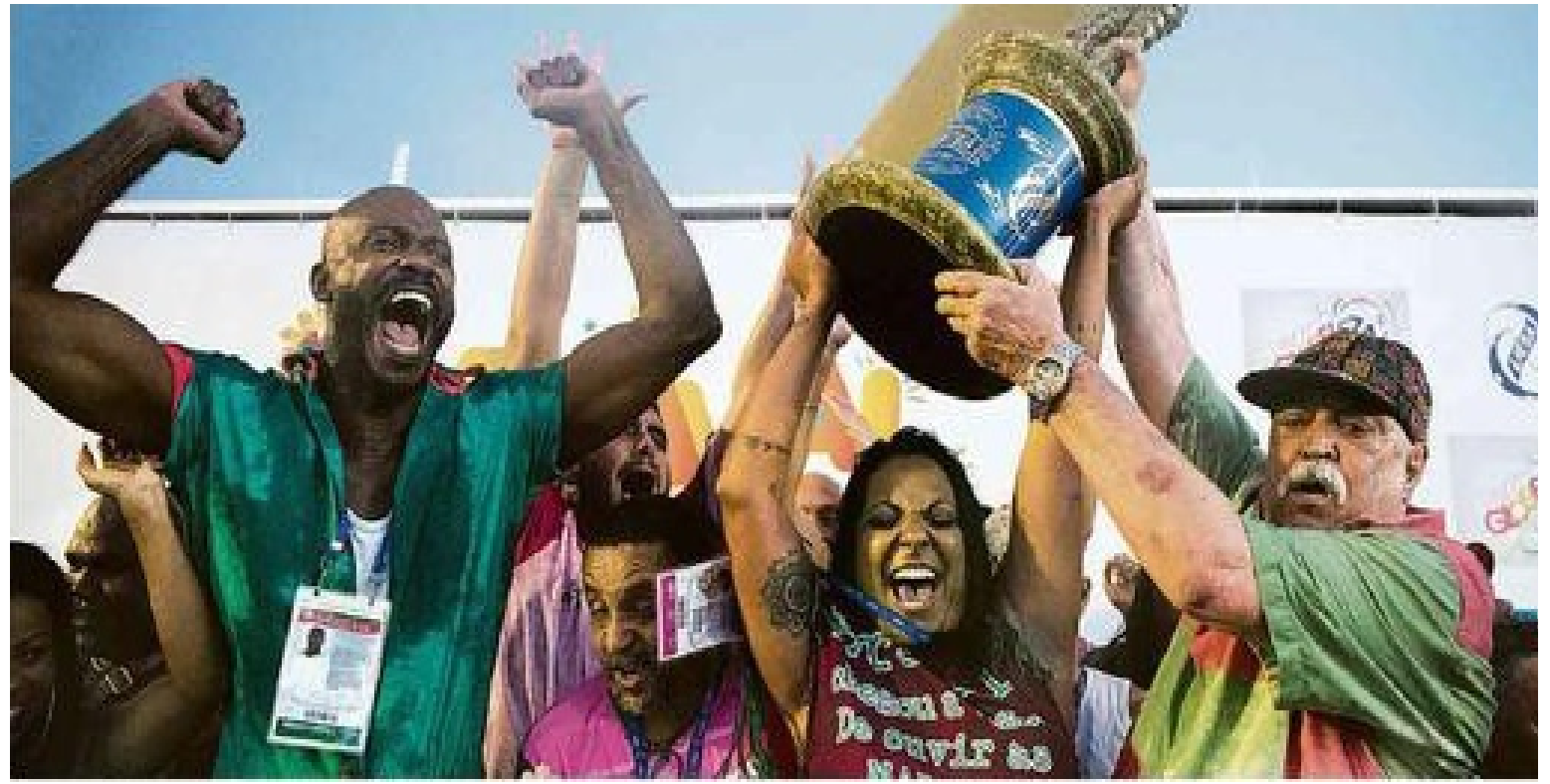

Figura 4: Ambiência de euforia

Fonte: Folha de S.Paulo.

Segundo Gielow (2014), este gesto foi uma das marcas dos movimentos comunistas alemães que disputavam o poder com os nazistas na Alemanha do pós-Primeira Guerra e, em 1926, tornou-se símbolo da ala militar do Partido Comunista da Alemanha, liderado por Ernst Thälmann (1886-1944). Este mesmo gesto foi também utilizado durante a Guerra Civil Espanhola (1936-1939), por grupos contrários aos fascistas liderados por Francisco Franco. Ainda, após a Segunda Guerra Mundial, o gesto alcança outros grupos, como as alas mais radicais do movimento pelos direitos civis dos negros americanos, na década de 1960. Nas mídias circulam fotos de medalhistas negros americanos, 
nos pódios da Olímpiada do México, em 1968, que repetem este gesto. Na mesma representação visual, outros braços, que não os do negro, mantêm a taça - o troféu conquistado - em destaque e no alto; os sorrisos espontâneos e abertos dos fotografados confirmam a alegria pela conquista, o que dá ao registro uma ambiência de euforia e de resistência. Os interpretantes gerados conferem às comunidades, vinculadas à escola de samba, uma posição de destaque, o que contribui para firmar a sua identidade cultural no presente, no lugar em que vivem.

Na mesma página, uma outra representação visual (Figura 5), exibe um momento de conflito em um dos blocos, durante desfile na cidade do Rio de Janeiro. Aqui, tal registro pode gerar interpretantes que associam o negro, bem como o carnaval - a conflito, desordem, desorganização. A representação visual não foi a sorteada para a categoria, mas consideramos pertinente mencioná-la pelo fato de estar na mesma página do jornal.

Conforme Rangel et al. (2019), os blocos carnavalescos levaram 3,6 milhões de pessoas às ruas, segundo dados da agência municipal de turismo do Rio de Janeiro. O bloco Fervo da Lud (desfile do bloco da cantora Ludmila) atraiu cerca de 1,2 milhões de pessoas. Com o objetivo de conter momentos de desordem que eclodiram, a polícia militar lançou bombas de efeito moral. Cerca de 217 pessoas foram atendidas nos postos de saúde montados no centro da cidade. Vale ressaltar que os foliões satirizavam os candidatos - "laranjas" do PSL -, então partido do atual presidente Jair Bolsonaro, além de fazerem outras críticas ao seu governo. Assim, a negrura pode ficar associada, pelo leitor, a experiências de êxito e de conflito envolvendo o carnaval. 


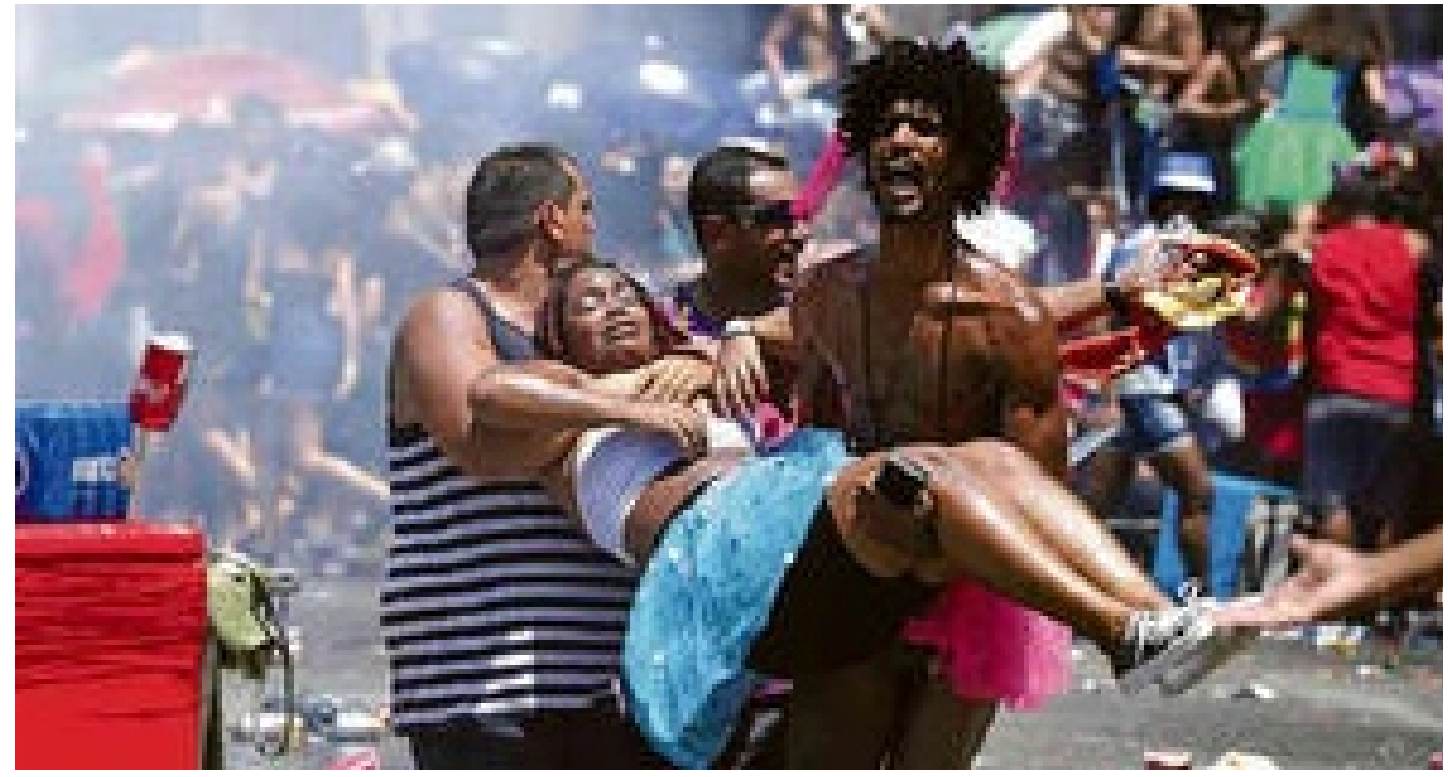

Figura 5: Confusão no bloco Fervo da Lud, no Rio de Janeiro Fonte: Foto de Marcelo de Jesus, de 5 de março de 2019.

A gravura (Figura 6) ilustra a história de Mila e foi posta na categoria pintura. Em notícia ilustrada por esta modalidade de representação visual, Varella (2019) conta a história da paulistana Mila, que vive um uma favela na cidade de São Paulo. Independentemente da história, pode-se observar que, na representação visual, o corpo de uma afrodescendente compõe a cidade de São Paulo.

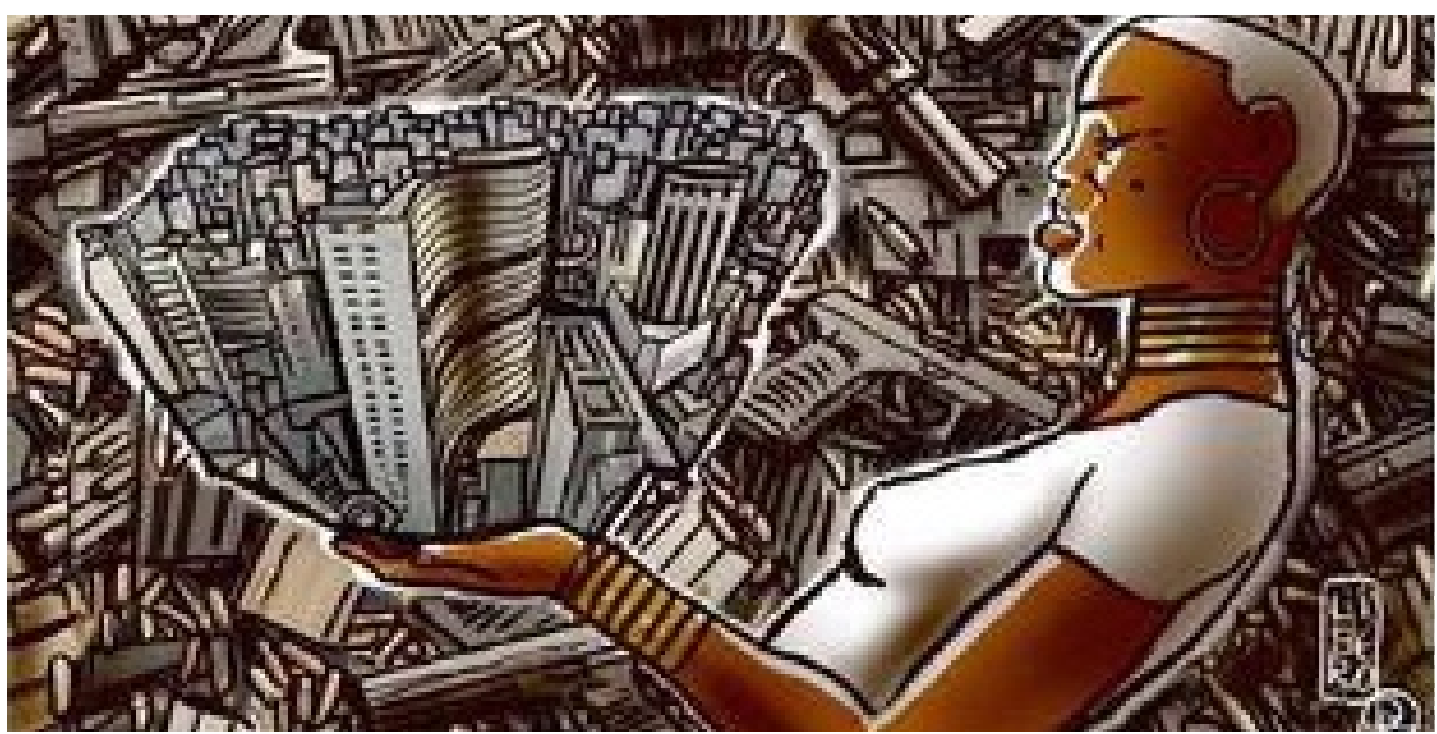

Figura 6: Caos e ordem

Fonte: Folha de S.Paulo. 
As múltiplas linhas pretas, sobre um fundo acinzentado, sugerem movimento, desordem. Mas entre essas linhas e com elas emerge uma região branca que sugere tranquilidade, paz. Deste modo, a representação visual parece se fazer um sinsigno indicial remático ao gerar efeitos ambíguos vinculados aos pares ordem/ desordem, tranquilidade/agitação e violência/paz. Por outro lado, essas mesmas linhas, sobre as mãos da mulher negra, desenham edifícios gigantescos, que levam o intérprete a associar à representação visual o edifício Copan e o edifício do Hotel Hilton, do centro da cidade de São Paulo, na Avenida Ipiranga; enquanto as linhas pretas do plano de fundo desenham armas e munições, que podem levar o intérprete a associá-la à violência, presente em comunidades da grande São Paulo. A parte superior do corpo de uma mulher negra - em meio ao movimento intrincado das linhas pretas sobre um fundo acinzentado - é uma massa densa e suave, branca -, é uma força que vence a desordem, a violência. Nesses momentos, a representação visual se faz sinsigno indicial dicente que, agregada ao texto, parece exibir a própria Mila e toda sua força.

Segundo Varella (2019), Mila nasceu em uma das comunidades mais pobres de São Paulo. Ela fugiu de casa quando tinha dez anos, depois de ser estuprada pelo padrasto, e passou a viver na Praça da Sé, no centro de São Paulo. Nas ruas conhece Dora, uma menina de 14 anos que a adotou, ou seja, ela passou a ser a "mãe de rua" de Mila. Aos 23 anos se casou com o filho de um falsificador de documentos da região, e foi trabalhar com o sogro. Mila dá à luz um casal de gêmeos. Nesse momento feliz de sua vida, o esposo e o sogro são assassinados. Ela assume o escritório de falsificação de documentos e cria seus filhos com educação. Eles nunca fumaram, usaram droga ou foram a uma delegacia. São donos de imóveis e estão na universidade. A filha estuda na Universidade de São Paulo e o filho, em uma universidade particular.

Na página do jornal, agregada ao texto, a representação visual pode funcionar como complemento, atribuindo-Ihe um potencial qualitativo maior, contribuindo para a geração de interpretantes dinâmicos - emocionais e lógicos -, que podem levar o intérprete a refletir sobre as dificuldades enfrentadas pela mulher negra em uma cidade como São Paulo, que é também palco de violência. Tais interpretantes contribuem para mostrar que o processo de construção da 
identidade cultural do Negro - e da mulher Negra, no caso - alcança patamares mais amplos, ao tentar dizer quem é ela num determinado território.

Os aspectos de lei, regra, normas ou convenções - vinculados às cores contribuem para reforçar os efeitos dos aspectos ambíguos mencionados. Isto porque a cor cinza que forma um suporte para as infinitas linhas pretas, leva o intérprete a associar a representação visual, segundo Chevalier e Gheerbrant (2008), à morte ou ao luto, enquanto a cor branca, a ritos de passagem. Assim, o jogo de cores pode protagonizar a passagem, a vitória de uma mulher que venceu a violência, a humilhação, o desrespeito.

Para a categoria publicidade selecionamos a representação visual (Figura 7) que está na categoria publicidade/produtos.

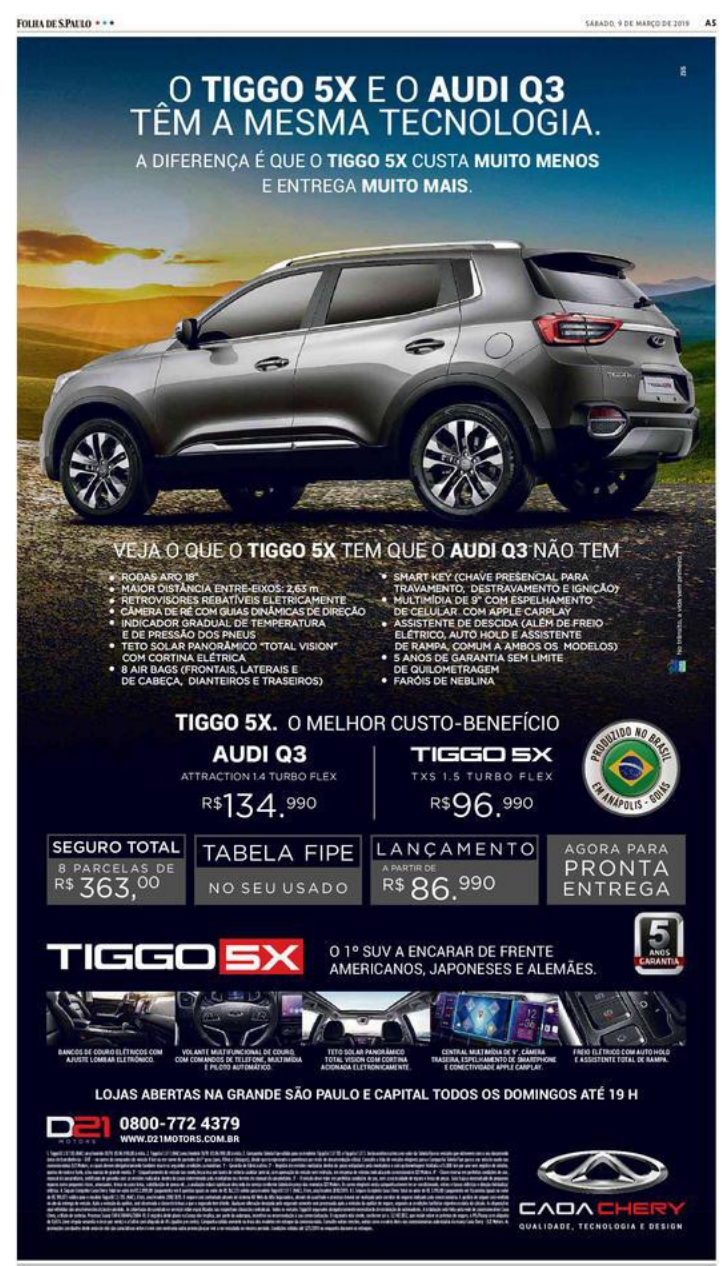

Figura 7: Publicidade "CARRO -TIGGO 5X" Fonte: Folha de S.Paulo. 
Tal representação é um sinsigno, pois é um existente, algo real, que, na relação com o objeto, prevalece como índice. Como tal impõe um olhar observacional, que leva o intérprete a identificar a peça publicitária do carro, na cor cinza, da marca chinesa Chery - Tiggo 5X, distribuído no Brasil desde o final de 2018 pelo distribuidor CAOA. O carro está sobre pedras acinzentadas, em primeiro plano. No segundo plano, há montanhas e o nascer do sol, que lança seus raios sobre as montanhas e o carro. Sobre o plano de fundo em tons azulados, na parte superior da representação visual, estão distribuídas, em letras brancas, informações sobre o produto, e outras imagens do interior do carro estão na parte inferior. Trata-se de uma peça publicitária que prima por deixar visível ao intérprete todas as informações úteis sobre o produto, sem deixar de compará-lo com um carro associado à alta tecnologia. Os interpretantes dinâmicos gerados traduzem aspectos de identificação do produto à mostra.

São poucos os aspectos qualitativos que podem contribuir para a geração de interpretantes emocionais, que suscitam conjeturas em relação ao carro. Se, por alguns instantes, tais aspectos qualitativos prevalecerem ou derem vez ao olhar contemplativo, então a peça publicitária se faz sinsigno indicial remático. Vejamos o que o olhar contemplativo pode captar. O carro, amplamente iluminado, impõe-se ao olhar do intérprete, mas emerge em meio a uma atmosfera de tranquilidade, leveza, com um nascer do sol que deixa o céu bordado por um amarelo radiante e um azul suave. O azul contribui para que o intérprete permaneça em contemplação, uma vez que, segundo Farina et al. (2006, p. 114), tal cor "transmite a sensação do movimento para o infinito", o que pode suscitar conjeturas envolvendo o novo carro. Iluminado, ele nasceu para brilhar, graças à tecnologia que o torna similar a um carro de outra marca, reconhecida mundialmente (um Audi Q3, tecnologia alemã).

Os raios solares agregam novos significados ao carro. Conforme Chevalier e Gheerbrant (2008, p. 836), o sol é "fonte da luz, do calor, da vida" e, ainda, os raios solares "manifestam as coisas". A luz, segundo Lacy (1996, p. 136), "é um espirito que emana do sol - cada raio de luz é uma força poderosa que 
penetra na matéria". Assim, ao receber os raios solares, a coisa se faz carro, como algo que recebeu uma luz divina/solar. Os interpretantes gerados - emocionais estão atados à força desse novo carro. A cor preta aparece camuflada também na cor do carro - cinza - que mescla as cores preta e branca. Nesse contexto, a cor cinza e os raios solares sugerem elegância, requinte, parecem exibir algo misterioso, inacessível.

Segundo Lacy (1996, p. 136) "os raios solares são as únicas coisas capazes de sustentar, alimentar e intensificar o fluxo vital do homem". Os raios solares atuam em favor da regeneração e da ressurreição. E ainda o reflexo dos raios solares "traz a sabedoria e o conhecimento". A luz que parece vir na direção do intérprete faz que ele, munido de sabedoria e conhecimento, pense em valer-se da força desse carro, o que pode levar o intérprete a novas ações, a transformar suas concepções sobre carros chineses ou produtos chineses em geral. A ambiência, construída com o jogo de cores, formas, texturas e com os simbolismos que as impregnam, pode levar o intérprete a fazer conjeturas sobre a beleza e o poder do carro, sobre a tecnologia que Ihe confere, além de ótimo desempenho, requinte e elegância.

A representação visual, na mira de um olhar mais especializado, um intérprete com conhecimentos de publicidade e também sobre o produto e a marca em questão pode se fazer legissigno simbólico e os efeitos podem ser emocionais, reativos ou lógicos. Ao analisar as técnicas empregadas na sua produção, o intérprete pode apreciar o processo de criação nela engendrado, selecionando alguns aspectos para incorporar a suas futuras criações. Pode também rejeitar todos. Nesse sentido, há aspectos cognitivos envolvidos que podem propiciar a transformação de crenças do intérprete em relação a processos criativos na publicidade. A peça pode se fazer legissigno simbólico, que leva, após sucessivas semioses envolvendo a peça, a mudanças de hábito do intérprete. Interessante notar que, talvez para tentar amenizar os efeitos de crenças sobre a qualidade dos produtos chineses, a peça mostra, no lado direito do intérprete que olha para ela, um selo de qualidade - com uma bandeira 
do Brasil, arredondada - atestando que se trata de um carro produzido no Brasil. As palavras - "PRODUZIDO NO BRASIL ANÁPOLIS GOIÁS" - circundam a bandeira, em letras maiúsculas, sugerindo força e comprometimento.

Os conhecimentos mais específicos sobre o produto e sobre linguagem visual podem compor o processo de criação da peça, o que pode ser identificado por um olhar de um intérprete especialista no assunto. As linhas curvas, conforme Farina et al. (2006), são abrangentes, insistentes e quentes, o que faz do Tiggo 5X um carro intenso, envolvente. A cor acinzentada, que envolve a cor preta, segundo Farina et al. (2006), ao mesmo tempo que parece angustiante também representa a seriedade, a nobreza, o requinte. A escrita "TIGGO 5X E AUDI Q3 tem a mesma tecnologia - a diferença é que o TIGGO 5X custa muito menos e entrega muito mais", na cor branca sobre o fundo azulado, conforme Farina et al. (2006), constrói uma ambiência de simpatia, para produtos e serviços que precisam informar de sua segurança e estabilidade. Assim, a representação visual - com um fazer publicitário incorpora a negrura vinculada a uma ambiência requintada, robusta.

Quanto às demais representações visuais, optamos por exibir os resultados das análises, destacando efeitos prováveis para elas, nas categorias: celebridade, cotidiano, entretenimento, pintura e publicidade (Tabela 1 ).

\begin{tabular}{|c|c|c|c|}
\hline $\begin{array}{c}\text { Categoria } \\
\text { (quantidade) }\end{array}$ & Contexto & $\begin{array}{c}\text { Aspecto } \\
\text { preponderante }\end{array}$ & $\begin{array}{c}\text { Efeitos ou modalidades de interpretantes } \\
\text { que prevalecem para a negrura }\end{array}$ \\
\hline \multirow[b]{2}{*}{ Celebridade } & Música & \multirow[b]{2}{*}{$\begin{array}{l}\text { pistas que } \\
\text { remetem ao real }\end{array}$} & $\begin{array}{l}\text { Interpretantes vinculados à identificação das } \\
\text { pessoas apresentadas }\end{array}$ \\
\hline & $\begin{array}{l}\text { Dança } \\
\text { Esporte } \\
\text { TV } \\
\text { Cinema }\end{array}$ & & $\begin{array}{l}\text { Interpretantes vinculados à alegria, à vitória, } \\
\text { ao sucesso e ao luxo com possibilidades de } \\
\text { associação do Negro a situações exitosas, ou ainda, } \\
\text { que reforçam o estereótipo do Negro, portador de } \\
\text { "dons naturais" para a música, para a dança, } \\
\text { como algo que está no sangue, que é da raça. }\end{array}$ \\
\hline \multirow[b]{2}{*}{ Cotidiano } & Pobreza & \multirow[b]{2}{*}{$\begin{array}{l}\text { pistas que } \\
\text { remetem ao real }\end{array}$} & \multirow[b]{2}{*}{$\begin{array}{l}\text { Interpretantes que colocam o Negro em } \\
\text { situações de inferioridade, de exclusão. } \\
\text { Interpretantes vinculados à precariedade, } \\
\text { à desordem. }\end{array}$} \\
\hline & $\begin{array}{l}\text { Favela } \\
\text { Manifestações } \\
\text { de rua } \\
\text { Eventos } \\
\text { esportivos }\end{array}$ & & \\
\hline
\end{tabular}




\begin{tabular}{|c|c|c|c|}
\hline $\begin{array}{c}\text { Categoria } \\
\text { (quantidade) }\end{array}$ & Contexto & $\begin{array}{l}\text { Aspecto } \\
\text { preponderante }\end{array}$ & $\begin{array}{c}\text { Efeitos ou modalidades de interpretantes } \\
\text { que prevalecem para a negrura }\end{array}$ \\
\hline Entretenimento & $\begin{array}{l}\text { Eventos musicais e } \\
\text { culturais, carnaval, } \\
\text { desfiles de moda }\end{array}$ & $\begin{array}{l}\text { pistas que } \\
\text { remetem ao real }\end{array}$ & $\begin{array}{l}\text { Interpretantes que suscitam questões sobre o } \\
\text { processo de construção da identidade do cultural } \\
\text { do Negro, que reforçam seus dons artísticos e } \\
\text { que vinculam a cor preta ao luxo e à elegância }\end{array}$ \\
\hline Pintura & $\begin{array}{l}\text { Violência urbana } \\
\text { Cultura brasileira }\end{array}$ & $\begin{array}{l}\text { Aspectos } \\
\text { sugestivos, que } \\
\text { suscitam } \\
\text { conjeturas }\end{array}$ & $\begin{array}{l}\text { Interpretantes emocionais e lógicos que } \\
\text { associam o Negro ao sincretismo religioso, } \\
\text { às turbulências da vida urbana e ao processo } \\
\text { de construção da identidade cultural que } \\
\text { mescla o passado (de sofrimento e vinculado } \\
\text { à escravidão) e o presente (de luta). }\end{array}$ \\
\hline Publicidade & $\begin{array}{l}\text { Destaque para o } \\
\text { produto }\end{array}$ & $\begin{array}{c}\text { Jogo entre } \\
\text { aspectos quali- } \\
\text { tativos (formas, } \\
\text { cores, texturas) e } \\
\text { referenciais (que } \\
\text { permitem identifi- } \\
\text { car o produto) }\end{array}$ & $\begin{array}{l}\text { Interpretantes que vinculam a cor preta } \\
\text { à elegância, estilo, requinte. }\end{array}$ \\
\hline
\end{tabular}

Tabela 1: Resultados das análises das representações visuais

Fonte: Elaborada pelas autoras.

\section{Considerações Finais}

A partir das análises das representações visuais que compõem a amostra selecionada, podemos enfatizar que novos significados são agregados à negrura, principalmente pela publicidade. A cor preta predomina nas representações visuais em que há pessoas negras e nas peças publicitárias de produtos ou marcas. Com isso, à negrura são agregados significados vinculados ao requinte, à elegância, à alegria, bem como à precariedade e à desordem. Mas, com a presença do Negro, há reforço de estereótipos da raça negra - aquela que possui dons para a música, a dança -, que sinalizam para um processo de construção de identidade cultural que não se desvincula do passado - a escravidão, a África-, mas tenta alçar voos para mostrar quem é no contexto em que vive.

Os interpretantes emocionais, efeitos predominantes para representações visuais alocadas na categoria publicidade ou pintura, contribuem para a construção de um tecido qualitativo vinculado à negrura, que poderá permear a geração de interpretantes de qualquer signo que incorpore a cor preta em futuras semioses. 


\section{Referências}

CHEVALIER, J.; GHEERBRANT, A. Dicionário de símbolos. Rio de Janeiro: José Olympio, 2008.

DRIGO, M. O.; SOUZA, L. Aulas de semiótica peirceana. São Paulo: Annablume, 2013.

FARINA, M. et al. Psicodinâmica das cores em comunicação. São Paulo: Edgard Blücher, 2006.

GIELOW, I. Punho cerrado é herança política do século XX. Folha de S.Paulo, São Paulo, 4 fev. 2014. Disponível em: https://bit.ly/3yPbpcb. Acesso em: 10 dez. 2021.

LACY, M. L. O poder das cores no equilíbrio dos ambientes. São Paulo: Pensamento, 1996.

MAISONAVE, F. Prefeitura infla número de acolhidos e nega acesso da Folha a abrigo. Folha de S.Paulo, São Paulo, 12 mar. 2019. Disponível em: https://bit.ly/3FuWmGM. Acesso em: 10 fev. 2020.

MBEMBE, A. Crítica da razão negra. Lisboa: Antígona, 2017.

PASTOUREAU, M. História de uma cor. São Paulo: Senac, 2011.

PEIRCE, C. S. The collected papers of Charles Sanders Peirce: elements of logic. Cambridge: Harvard University Press, 1932.

PEIRCE, C.S. The collected papers of Charles Sanders Peirce: pragmatism and pragmaticism. Cambridge: Harvard University Press, 1934. 
RANGEL, S. et al. Carnaval tem público recorde, tons de laranja e polêmica. Folha de S.Paulo, São Paulo, 7 mar. 2019. Cotidiano. Disponível em: https:// bit.ly/3qj41Se. Acesso em: 10 jan. 2020.

SANTAELLA, L. Semiótica aplicada. São Paulo: Cengage Learning, 2018.

SANTAELLA. L. O que é Semiótica? São Paulo: Brasiliense, 2011.

VARELLA, D. Mila fugiu de casa aos dez anos, viveu para o trabalho e a família e hoje sente orgulho. Folha de S.Paulo, São Paulo, 3 mar. 2019. Ilustrada. Disponível em: https://bit.ly/3H2b08X. Acesso em: 10 jan. 2020.

submetido em: 19 dez. 2020 | aprovado em: 7 maio 2021 